\title{
Barriers to Instructional Technology Use Among Malaysian Public University Academicians
}

\begin{abstract}
Despite the benefits of technology use in instruction, in general it has not been widely accepted within institutions of higher education in both developed and developing nations. Previous studies have indicated that its use by faculty members in higher education has been generally minimal. This study examined: i) the nature and extent of use of certain instructional technologies by university lecturers, and ii) reasons that has hindered the utilization of instructional technologies by lecturers in a Malaysian public university. The findings of the study revealed that despite the growing availability of newer technologies and the greater familiarity with technologies by faculty members, they reportedly continue to rely on the more familiar technologies (such as audiovisual media and word processing) for their class instruction. The widespread use of the newer and more innovative technologies (such as presentation software, computer conferencing, distance learning technologies and multimedia technologies) by the lecturers seems to be occurring at a slow rate. On the basis of the responses to reasons for not using a instructional technology, the primary reasons most frequently reported by were unavailability of facilities or resources, technology not necessary, lack of knowledge and skills, and lack of time.
\end{abstract}

Keyword: Instructional Technology Use, Barriers to Technology Use, Nature of Technology Use 